\title{
Enseñanza de Lenguas de Frontera en la Triple Frontera ${ }^{1}$
}

\author{
Ensino de Línguas de Fronteira na Tríplice Fronteira \\ Teaching Bordier Languages in the Triple Frontier
}

\author{
Cinthia Itatí Gabriela Minuzzo \\ Simone Beatriz Cordeiro Ribeiro ${ }^{3}$
}

\begin{abstract}
Resumen
Este articulo pretende dar a conocer el Proyecto de Extensión "Ensino de Linguas de Fronteira através de práticas Interdisciplinares", de la Universidad Federal de la Integración Latinoamericana, llevado a cabo en la ciudad de Foz do Iguaçu, Paraná. Destinado a alumnos y docentes de la Enseñanza Fundamental I y demás miembros de la comunidad educativa interesados, el mismo está relacionado al Proyecto de Investigación "Ensino de linguas de fronteira sob a perspectiva de fronteira geográfica enunciativa" y también correlacionado al Proyecto de Extensión "Ensino de Português como Língua Adicional no Ensino Fundamental I". Dentro de la perspectiva de frontera geográfica enunciativa, las lenguas de frontera ultrapasan los límites geográficos e se constituyen como lenguas de integración, de este modo, el contacto linguístico-enunciativo entre los sujetos involucra también contenidos políticos y socioculturales. La metodología y fundamentación teórica utilizada para la ejecución de las actividades propuestas para la enseñanza de Lengua Española están sustentadas en los presupuestos de la Lingüística Aplicada, Sociolingüística, Políticas y Derechos Lingüísticos con enfoque en la enseñanza de Lenguas de Frontera.
\end{abstract}

Palabras claves: Enseñanza de Lenguas de Frontera; Interdisciplinaridad; Lingüística Aplicada; Políticas Lingüísticas; Triple Frontera.

\section{Resumo}

Este artigo objetiva apresentar o Projeto de Extensão "Ensino de Línguas de Fronteira através de práticas interdisciplinares", da Universidade Federal da Integração Latino-Americana, em desenvolvimento na cidade de Foz do Iguaçu, Paraná. Destinado aos alunos e docentes do Ensino Fundamental I e demais membros da comunidade educativa interessados, o mesmo está relacionado ao Projeto de Pesquisa "Ensino de línguas de fronteira sob a perspectiva de fronteira geográfica enunciativa" e também, correlacionado ao Projeto de Extensão "Ensino de Português como Língua Adicional no Ensino Fundamental I". Na perspectiva de fronteira geográfica enunciativa, as línguas de fronteira ultrapassam os limites geográficos e constituem-se como línguas de integração, deste modo, o contato linguístico-enunciativo entre os sujeitos envolve também conteúdos

\footnotetext{
${ }^{1}$ Este texto procede del desarrollo de la Acción de extensión "Ensino de Línguas de Fronteira através de práticas interdisciplinares" y del Proyecto de Investigación "Ensino de línguas de fronteira sob a perspectiva de fronteira geográfica enunciativa", ambos de la Universidad Federal de la Integración Latinoamericana, coordinados por la Docente Simone Beatriz Cordeiro Ribeiro y ejecutados por la Discente Cinthia Itatí Gabriela Minuzzo. Trabajo presentado en el I Seminário Latino-Americano de Estudos em Cultura - SEMLACult, Foz de Iguazu/PR, Brasil, 2017.

${ }^{2}$ Graduación en Letras Artes e Mediação Cultural en la Universidad Federal de la Integración Latinoamericana UNILA; Foz de Iguazu, Paraná, Brasil; Estudiante becario (PROEX/UNILA) del Proyecto de Extensión "Ensino de Línguas de Fronteira através de práticas interdisciplinares" e integrante del Proyecto de Investigación "Ensino de línguas de fronteira sob a perspectiva de fronteira geográfica enunciativa"; cig.minuzzo.2017@aluno.unila.edu.br

${ }^{3}$ Doctora en Letras - Lenguaje y Sociedad; Docente de la Universidad Federal de la Integración Latinoamericana - UNILA, Foz de Iguazu, Paraná, Brasil; Ciclo Comum de Estudos; simone.ribeiro@unila.edu.br
} 
políticos e socioculturais. A metodologia e a fundamentação teórica utilizada para a execução das atividades propostas ao ensino da Língua Espanhola estão sustentadas nos pressupostos da Linguística Aplicada, Sociolinguística, Políticas e Direitos Linguísticos com enfoque no ensino de Línguas Fronteiriças.

Palavras-chave: Ensino de Línguas de Fronteira; Interdisciplinaridade; Linguística Aplicada; Políticas Linguísticas; Tríplice-Fronteira.

\section{Summary}

This article aims to present the Extension Project "Ensino de Línguas de Fronteira através de práticas interdisciplinares", from the Federal University of Latin American Integration, under development in the city of Foz do Iguaçu, Paraná. Designated for the students and teachers of Elementary School I and other interested members of the educational community, the same is related to the Research Project " Ensino de linguas de fronteira sob a perspectiva de fronteira geográfica enunciativa" and also, correlated to the Extension Project "Ensino de Português como Língua Adicional no Ensino Fundamental I". In the perspective of a geographic frontier enunciatory, bordier languages extend beyond geographic limits and are constituted as integration languages, in this way, the linguistic-enunciative contact between the people also involves political and sociocultural contents. The methodology and theoretical basis used for the execution of the activities proposed for the education of the Spanish Language are based on the assumptions of Applied Linguistics, Sociolinguistics, Linguistic Rights and Policies with a focus on the teaching of Frontier Languages.

Keywords:Teaching Border Languages; Interdisciplinarity; Applied Linguistics; Linguistic Policies; Triple Frontier.

\section{Introducción}

A excepción de Surinam, Guyana y Guayana Francesa, todos los países fronterizos con Brasil hablan español y lo tienen como lengua oficial, lo que es muy importante desde el punto comercial, económico, cultural y personal. Esta relación entre las dos lenguas, española y portuguesa, repercute en una relación histórica de colonización Española y Portuguesa, así como tienen aún en común la formación lingüística de sus lenguas originarias del latín. Dicha situación de interacción entre los habitantes latinoamericanos demuestra que el contacto entre el español y el portugués, en estos espacios fronterizos, son evidentes, constantes y ni siempre amistosos.

La similitud entre las lenguas portuguesa y española posibilita que los habitantes, principalmente de la frontera, se comuniquen en sus propias lenguas o en la lengua del otro en contextos educacionales, comerciales, culturales o turísticos. A vezes incluso en Portunhol, un hablar de solidaridad e intercambio que ocurre en los dos lados de la frontera (RIBEIRO, $2015 ; 2017)$.

En el Mercosur, tanto la Lengua Española como la Lengua Portuguesa están acopladas a la formación profesional y al comercio internacional, lo que permite decir que el aprendizaje del portugués es tan necesario como el del español en América Latina, pues la enseñanza y el aprendizaje de lenguas debe considerar el "conocimiento adecuado para entender a su realidad 
y la realidad de nuestro mundo globalizado, bien como para evaluar sus posibilidades de actuación en sociedad ${ }^{4 \prime}$ (FERREIRA e SANTOS, 2010, p. 138).

Así, además de los límites cartográficos que demarcan físicamente el espacio, determinando condiciones de poder, "la vida de la frontera, el habitar la frontera [significa], para los que en ella viven, mucho más, porque ella ya se define en sí misma como un espacio de contacto, un espacio en el que se tocan culturas, etnias, lenguas, naciones ${ }^{5}$ " (STURZA, 2006, p.26 - grifos de la autora), pues el vivir e interactuar en la frontera se construye también de contenido social, una vez que la "frontera se da en y por el lenguaje" y "los preconceptos, envés de ser eliminados, serán colocados en evidencia" ${ }^{6 "}$ (CAMPIGOTO, 2000, p. 17).

Partiendo del contexto de Triple Frontera Brasil - Paraguay - Argentina, vivenciado en la ciudad de Foz do Iguaçu, Paraná, como puede ser observado en el Mapa 1:

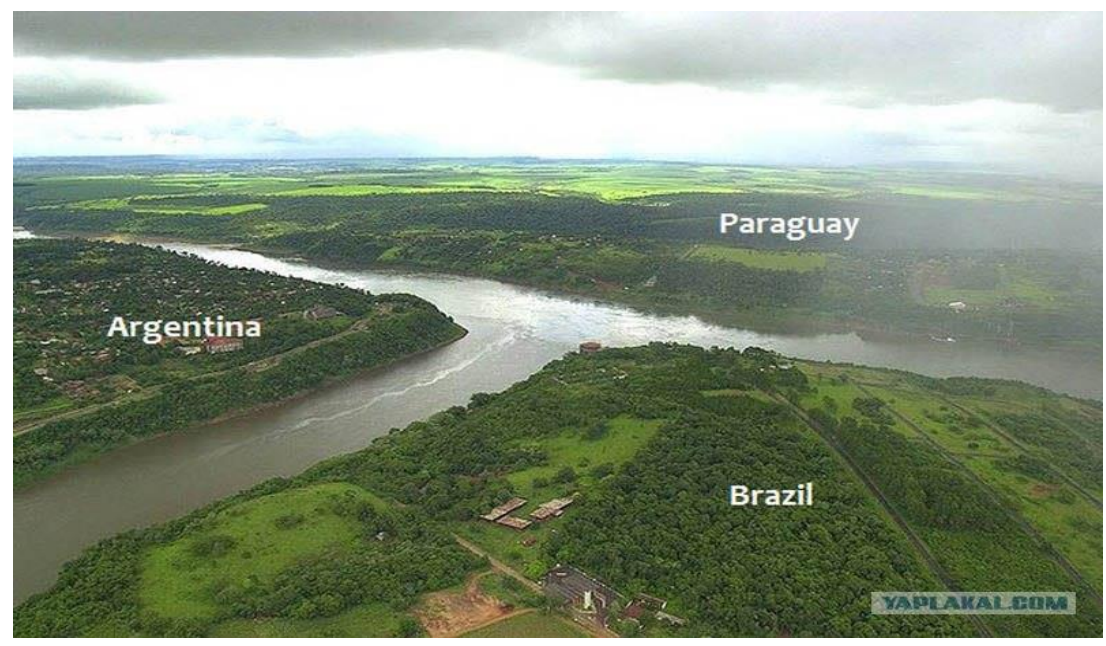

Mapa 1 - Imagen de la Triple Frontera

Fonte: << http://wikimapia.org/26932/pt/Marco-das-Tr\%C3\%AAs-Fronteiras-Tr\%C3\%ADplice-Fronteira > .

Y resaltando el carácter de Universidad Bilingüe de la UNILA (Universidad Federal de la Integración Latinoamericana), surgió la creación del proyecto de Extensión "Ensino de Línguas de Fronteira através de práticas interdisciplinares”, considerando no solo a las

\footnotetext{
${ }^{4}$ Fragmento original: "conhecimento adequado para entender a sua realidade e a realidade de nosso mundo globalizado, bem como para avaliar suas possibilidades de atuação em sociedade" (FERREIRA e SANTOS, 2010, p. 138).

${ }^{5}$ Fragmento original: "a vida da fronteira, o habitar a fronteira [significa], para quem nela vive, muito mais, porque ela já se define em si mesma como um espaço de contato, um espaço em que se tocam culturas, etnias, línguas, nações" (STURZA, 2006, p.26 - grifos da autora).

${ }^{6}$ Fragmento original: "fronteira se dá na e pela linguagem" y "os preconceitos, ao invés de serem eliminados, serão colocados em evidência" (CAMPIGOTO, 2000, p. 17).
} 
fronteras como geográficas sino también como lingüísticas, teniendo en cuenta el concepto de frontera geográfica enunciativa ${ }^{7}$, en el cual las lenguas de frontera ultrapasan los límites geográficos y se constituyen como lenguas de integración, dejando de lado los limites nacionales o internacionales, para así consolidar un espacio de enunciación fronterizo.

De este modo, a través de discusiones y de reflexiones sobre Políticas Lingüísticas, situación de frontera y enseñanza de Lenguas de Frontera se establece la tesitura de este texto que tiene como objetivo dar a conocer dicho proyecto de extensión, insertado en la Triple Frontera y teniendo en cuenta el uso de la Lengua Española en escuelas de enseñanza primaria. Así, primeramente se hace una discusión acerca de las Políticas Lingüísticas, seguido del escenario fronterizo y la enseñanza de lenguas, después se hace una breve contextualización metodológica, exponiendo la base teórica para la creación y ejecución del proyecto, cómo este será implementado, en que consiste el curso de español y los resultados que se esperan obtener.

\section{Políticas Lingüísticas}

Según Calvet (2007), la política lingüística corresponde a la "determinación de las grandes decisiones referentes a las relaciones entre las lenguas y la sociedad" (CALVET, 2007, p. 11). A partir de ello, Rajagopalan (2013), añade, a la política lingüística, el termino planeamiento lingüístico que se refiere, "a su implementación" 9" (CALVET, 2007, p. 11), a su "transformación en realidad ${ }^{10 "}$ (OLIVEIRA, 2013, p. 1). Sobre esta perspectiva, la política y el planeamiento lingüístico corresponden a una "actividad humana resultante de la necesidad de encontrar una solución a un problema ${ }^{11 "}$ (CALVET, 2007, p. 21).

Delante de eso, se alerta a la necesidad

\footnotetext{
7 Ribeiro (2015), em sua tese de doutorado, utiliza o termo "enunciativa" agregado à expressão "fronteira geográfica", por entender que a fronteira não é apenas geográfica ou enunciativa, mas sim a junção de ambas, pois a fronteira caracteriza-se pela interação comunicativa existente no representativo de vozes que permeiam o Brasil e os países de Língua Espanhola, tanto pela expressão de línguas como de culturas em contato e em conflito nos dois lados da fronteira. Portanto, a expressão fronteira geográfica enunciativa caracteriza-se pela interação comunicativa existente no espaço fronteiriço (RIBEIRO, 2015).

${ }^{8}$ Fragmento original: "determinação das grandes decisões referentes às relações entre as línguas e a sociedade" (CALVET, 2007, p. 11).

${ }^{9}$ Fragmento original: “à sua implementação” (CALVET, 2007, p. 11).

${ }^{10}$ Fragmento original: “transformação em realidade” (OLIVEIRA, 2013, p. 1).

${ }^{11}$ Fragmento original: "atividade humana decorrente da necessidade de se encontrar uma solução para um problema” (CALVET, 2007, p. 21).
} 
[...] de una reforma lingüística del país que permita una reacción colectiva positiva frente a las nuevas demandas de la globalización y de la inclusión cultural y lingüística. Esa reforma cultural y lingüística pasa por la organización de las demandas de los hablantes, a través de sus representaciones, y de su contacto con lo legislativo, donde estas demandas se transforman en indicaciones de acción, por la capacitación de órganos de Estado directamente involucrados con la planificación lingüística, como ministerio de cultura, de educación, de ciencia y tecnología, secretarias estatales y municipales, las escuelas y los medios ${ }^{12}$ (OLIVEIRA, 2013, p. 13 - grifos nuestros).

A este respeto, Rajagopalan (2013), destaca que la política lingüística debe atender realmente las necesidades de la comunidad o el grupo al que se destina, intensificando la participación de los ciudadanos en las elecciones y determinaciones lingüísticas, pues intervención "significa entonces: trabajo en conjunto con las comunidades lingüísticas que conforman el país ${ }^{13} "$ (OLIVEIRA, 2005, p. 87).

$\mathrm{O}$ sea, es necesario que lo considerado urgente en una determinada sociedad sea respetado "antes de elaborar y promulgar una ley de cuño político lingüístico. Un planeamiento comprometido con el ámbito social deberá de modo improrrogable considerar las necesidades y las consecuencias de su aplicación en el seno de la sociedad ${ }^{14 ”}$ (RIBEIRO, 2017). Así, planificación, además de ser una manera de intervención, es la acción de poner en práctica las políticas linguiísticas y debe tener la participación de diferentes sujetos de la sociedad.

Esto también fue reiterado por von Borstel (2013), al acrecentar que las políticas lingüísticas se efectúan por medio de la planificación educacional cuando "existe un gran número de grupos de interés, aunque muchas veces no se tenga consciencia de los intereses

\footnotetext{
${ }^{12}$ Fragmento original: [...] de uma reforma linguística do país que permita uma reação coletiva positiva frente às novas demandas da globalização e da inclusão cultural e linguística. Essa reforma linguística passa pela organização das demandas dos falantes, através de suas representações, e do seu contato com o legislativo, onde estas demandas se transformam em indicação de ação, pela capacitação de órgãos de Estado diretamente envolvidos com a planificação linguística, como ministério de cultura, de educação, de ciência e tecnologia, secretarias estaduais e municipais, as escolas e as mídias (OLIVEIRA, 2013, p. 13 - grifos nuestros).

${ }^{13}$ Fragmento original: "significa então: trabalho conjunto com as comunidades lingüísticas que conformam o país” (OLIVEIRA, 2005, p. 87).

${ }^{14}$ Fragmento original: "antes mesmo de se elaborar e promulgar uma lei de cunho político linguístico. Um planejamento engajado no âmbito social deverá impreterivelmente considerar as necessidades e as consequências de sua aplicação no seio da sociedade" (RIBEIRO, 2017).
} 
linguíísticos y de la planificación lingüística de esos mismos grupos o de esa comunidad de inmigrantes y de frontera geográfica ${ }^{15} "$ (VON BORSTEL, 2013, p. 5).

A partir de ello, se percibe que la participación de la sociedad en las intervenciones políticas es fundamental y, además de ser una instancia a ser consultada, debería tener sus decisiones respetadas y llevadas en consideración, pues las políticas y planificaciones lingüísticas tienen que tener en cuenta las necesidades de la propia comunidad que será atendida. Debe partir de lo local para lo global y no al contrario, teniendo en cuenta las necesidades sociales contemporáneas y heterogéneas del mundo globalizado y multilingüe.

Sobre esto, Pereira y Costa (2011), al tratar sobre las relaciones entre bilingüismo e enseñanza en regiones de frontera geográfica, de inmigración y de indígenas, aclaran que

[...] la política lingüística está implícita en las practicas pedagógicas que buscan equilibrio entre las lenguas de los usuarios, aunque las instancias de enseñanza reflejen, documentalmente, la opción por una lengua en detrimento de otra(s). Tal opción es perceptible por la visibilidad y casi exclusivamente dada a una lengua y supresión de otras ${ }^{16}$ (PEREIRA e COSTA, 2011, p. 49).

Cuando en verdad podría ser desarrollada una enseñanza de lenguas desde la perspectiva plurilingüística, así como ya ocurre en algunas instituciones privadas del país. Desde esta perspectiva multilingüe que envuelve las Lenguas de Frontera y de elección de las mismas, Sturza (2006), aclara que la distribución de lenguas fronterizas "puede ser vista desde la perspectiva del hablante como la del investigador. En ambos casos, lo que sobresale es que las lenguas están reguladas por un juego de poder y dominio determinado por el factor político $^{17}$ " (STURZA, 2006, p. 22).

Delante de esto, "las lenguas de la frontera, al ser enunciadas, significan una política que las organiza y las distribuye ${ }^{18 "}$ (STURZA, 2006, p. 19). Esa distribución es, muchas

\footnotetext{
${ }^{15}$ Fragmento original: "há um grande número de grupos de interesse, embora muitas vezes não se tenha consciência dos interesses linguísticos e da planificação linguística desses mesmos grupos ou dessa comunidade de imigrantes e de fronteira geográfica" (VON BORSTEL, 2013, p. 5).

${ }^{16}$ Fragmento original: [...] a política linguística está implícita nas práticas pedagógicas que buscam equilíbrio entre as línguas dos usuários, embora as instâncias de ensino reflitam, documentalmente, a opção por uma língua em detrimento de outra(s). Tal opção é perceptível pela visibilidade e quase exclusivamente dada a uma língua e apagamentos de outras (PEREIRA e COSTA, 2011, p. 49).

${ }^{17}$ Fragmento original: "pode ser vista a partir tanto da perspectiva do falante como da do pesquisador. Em ambos os casos, o que sobressai é que as línguas são reguladas por um jogo de poder e de domínio determinado pelo fator político" (STURZA, 2006, p. 22).

${ }^{18}$ Fragmento original: "as línguas da fronteira, ao [se] enunciarem, significam uma política que as organiza e as distribui” (STURZA, 2006, p. 19).
} 
veces, determinada por cuestiones de interés y/o visiones homogeneizadas que apuntan al monolingüismo o que consideran apenas a las lenguas a partir de conceptos de status. En consecuencia, "la importancia de ser bilingüe o plurilingüe es enmascarada por el sustento de una política de monolingüismo ${ }^{19 ”}$ (RIBEIRO, 2015, p. 211). Situación que fortalece aún más el desarrollo de prácticas e investigaciones de carácter plurilingüístico.

\section{Situación de frontera y enseñanza de lenguas}

Las fronteras pueden ser entendidas como la divisa geográfica que permite el tránsito de los habitantes que en ella viven y que en la mayoría de las veces se autodenominan fronterizos. También se puede considerar a las fronteras como culturales, lingüísticas o étnicas. Estas relaciones son posibles porque el significado atribuido a la "línea de la frontera depende de los 'ojos del observador'20', (CAMPIGOTO, 2000, p. 11).

El habitar la frontera es extremamente desafiador, pues existe el constante conflicto del pertenecer o no, identidades fragmentadas y/renegociadas. Y estos conflictos pasan a percibirse en la educación, en la relación de profesor/alumno, alumno/alumno, pues enseñar y aprender en estos escenarios trae a la luz los sentimientos en relación a las lenguas. Ciertos prejuicios lingüísticos se revelan y el aprendizaje genera dificultades no solo para el alumno, sino también, para el docente al momento de enseñar.

De este modo al tener en cuenta al contexto como transfronterizo, la enseñanza de lenguas vinculada a las políticas lingüísticas se vuelve una necesidad emergente, de modo como afirma Rajagopalan (2011), "necesitamos dominar las dos cosas [política lingüística y enseñanza de lenguas] cada vez más. Tenemos que pensar la enseñanza de lenguas desde el abordaje, la metodología a ser adoptada en función de la política lingüística adoptada en el país ${ }^{21 "}$ (SILVA, SANTOS e JUSTINA, 2011, p. 5), y “adquirir/aprender y enseñar lenguas en las condiciones reales brasileñas $22 "$ (ALMEIDA FILHO, 2011, p. 16). Por eso, es necesario

\footnotetext{
${ }^{19}$ Fragmento original: “a importância em ser bilíngue ou plurilíngue é mascarada pel[o] sustento de uma política de monolinguismo” (RIBEIRO, 2015, p. 211).

${ }^{20}$ Fragmento original: "linha da fronteira depende dos 'olhos do observador'” (CAMPIGOTO, 2000, p. 11).

${ }^{21}$ Fragmento original: "precisamos atrelar as duas coisas [política linguística e ensino de línguas] cada vez mais. A gente tem que pensar o ensino de línguas desde a abordagem, a metodologia a ser adotada em função da política linguística adotada no país" (SILVA, SANTOS e JUSTINA, 2011, p. 5).

${ }^{22}$ Fragmento original: “adquirir/aprender e ensinar línguas nas condições reais brasileiras” (ALMEIDA FILHO, 2011, p. 16).
} 
un debate dirigido a "un plan de políticas que considere una visión de educación conforme a los desafíos de la sociedad actual ${ }^{23} "$ (MÓR, 2013, p. 233).

En este escenario de regiones que hacen uso del bilingüismo situacional o relativo, hay fuertes indicios de conflictos, generando actitudes positivas y negativas en las interlocuciones entre hablantes y educadores cuando son utilizadas las variedades lingüísticas con trazos bilingües, que "puede[n] llevar a los sujetos a una actitud de inquietud, de inseguridad, cuya consecuencia puede ser de amar y de odiar una de las lenguas de su repertorio en una actitud abiertamente antagónica ${ }^{24 ”}$ (PEREIRA e COSTA, 2011, p. 49). Por eso, es necesario, cuando se trata de estudios sobre la enseñanza y la formación continuada de profesores, que se investiguen los hablares utilizados en la esfera regional o local como prácticas de enseñanza y de aprendizaje.

Por lo tanto, se entiende que la enseñanza de lenguas extranjeras "necesita proveer al alumno del conocimiento adecuado para entender su realidad y la realidad de nuestro mundo globalizado, así como para evaluar sus posibilidades de actuación en sociedad ${ }^{25}$ " (FERREIRA e SANTOS, 2010, p. 138), pues "son tantas las razones a favor del aprendizaje de una" Lengua Extranjera ${ }^{26}$ (FERREIRA e SANTOS, 2010, p. 130).

Pensando justamente en la realidad de los alumnos brasileños, instaurada por la condición de Triple Frontera y por el contacto linguístico con la Lengua Española, que se refuerza la necesidad de una política y de una planificación lingüística para las redes públicas de enseñanza, considerando todo ese contexto de frontera geográfica enunciativa, pues el "hecho de que seamos vecinos es un motivo a más para que aprendamos su lengua y nos familiaricemos con su cultura ${ }^{27}$ " (SEDYCIAS, 2005, p. 39), una vez que "si hay una política

\footnotetext{
${ }^{23}$ Fragmento original: "um plano de políticas que considere uma visão de educação condizente com os desafios da sociedade atual" (MÓR, 2013, p. 233).

${ }^{24}$ Fragmento original: "pode[m] levar os sujeitos a uma atitude de inquietação, de insegurança, cuja consequência pode ser de amar e de odiar uma das línguas de seu repertório em uma atitude abertamente antagônica" (PEREIRA e COSTA, 2011, p. 49).

${ }^{25}$ Fragmento original: "precisa munir o aluno do conhecimento adequado para entender a sua realidade e a realidade de nosso mundo globalizado, bem como para avaliar suas possibilidades de atuação em sociedade" (FERREIRA e SANTOS, 2010, p. 138)

${ }^{26}$ Fragmento original: "são tantas as razões em favor da aprendizagem de uma" (FERREIRA e SANTOS, 2010, p. 130).

${ }^{27}$ Fragmento original: "fato de sermos vizinhos é um motivo a mais para aprendermos sua língua e nos familiarizarmos com sua cultura" (SEDYCIAS, 2005, p. 39).
} 
linguíistica educacional municipal con la ayuda de la comunidad y de los sectores económicos locales [...] talvez sea posible ${ }^{28 "}$ (VON BORSTEL, 2013, p. 5).

Se añade aún más el carácter globalizante, la formación profesional y el comercio internacional, sobre todo en el Mercosur que “ya sea por la globalización o por los diferentes tratados que Brasil ha firmado con sus socios del Mercosur, el español, como el inglés, se está convirtiendo en una lengua imprescindible por las necesidades de comunicación ${ }^{29}$, (SALINAS, 2005, p. 54).

A ese respecto, Sedycias (2005), cuando trata de la comunicación en el ámbito de América Latina, aclara que esta representa:

uno de los mercados más prometedores del nuevo siglo, el portugués y el español representan dos medios de comunicación más importantes para ese comercio global. Quien quiera comprar, ciertamente podrá hacerlo usando su lengua nativa (generalmente el vendedor se encarga de aprender la lengua de quien tiene dinero para adquirir sus productos). Por otro lado, quien quiera vender, tendrá que hacerlo con un buen conocimiento de la lengua y la cultura del comprador [...] $]^{30}$ (SEDYCIAS, 2005, p. 36 - grifos nuestros).

Como alerta el estudioso, es imprescindible, para quien quiera ampliar el intercambio comercial, utilizar la lengua de sus clientes, demostrando dominio y habilidad lingüística, pues en un "mundo que sirve de escenario para el contacto, el intercambio sin precedentes entre pueblos, el multilingüismo adquiere nuevas connotaciones. El ciudadano de este nuevo mundo emergente es, por definición, multilingüe ${ }^{31}$ ” (RAJAGOPALAN, 2003, p. 69).

En la Triple Frontera el sujeto puede comunicarse con otros sujetos, con otras culturas y con otras lenguas, esto significa "antes que nada, que el verdadero propósito de la

\footnotetext{
${ }^{28}$ Fragmento original: "se houver uma política linguística educacional municipal com a ajuda da comunidade e de setores econômicos locais [...] talvez seja possível" (VON BORSTEL, 2013, p. 5).

${ }^{29}$ Fragmento original: "seja pela globalização ou pelos diferentes tratados que o Brasil tem assinado com seus parceiros do Mercosul, o espanhol, como o inglês, está se tornando uma língua imprescindível por conta das necessidades de comunicação" (SALINAS, 2005, p. 54).

${ }^{30}$ Fragmento original: um dos mercados mais promissores do novo século, o português e o espanhol representam dois meios de comunicação mais importantes para esse comércio global. Quem quiser comprar, certamente poderá fazê-lo usando sua língua nativa (geralmente o vendedor se encarrega de aprender a língua de quem tiver dinheiro para adquirir seus produtos). Por outro lado, quem quiser vender, terá que fazê-lo com um bom conhecimento da língua e da cultura do comprador [...] (SEDYCIAS, 2005, p. 36 - grifos nuestros).

${ }^{31}$ Fragmento original: "mundo que serve de palco para o contato, o intercâmbio sem precedentes entre povos, o multilingüismo adquire novas conotações. O cidadão desse novo mundo emergente é, por definição, multilíngue" (RAJAGOPALAN, 2003, p. 69).
} 
enseñanza de lenguas extranjeras es formar individuos capaces de interactuar con personas de otras culturas y modos de pensar y actuar. Significa transformarse en ciudadano de mundo ${ }^{32}$ " (RAJAGOPALAN, 2003, p. 70 - grifos nuestros).

\section{Metodología}

El proyecto en cuestión pretende acercar a la comunidad la Lengua Española, partiendo de la red municipal de educación, específicamente en la enseñanza Primaria ${ }^{33}$, donde integrantes de la universidad a través de las prácticas de extensión brindarán un curso de Lengua Española a los niños de la $4^{\mathrm{a}}$ y $5^{\mathrm{a}}$ serie, de la escuela Padre Luigi Salvucci, buscando compartir con la sociedad los conocimientos desarrollados en la universidad.

El abordaje de enseñanza y de aprendizaje que se propone, está en correlato con la perspectiva de Lenguas de Frontera. Así, la enseñanza de la Lengua Española bajo este enfoque considera el espacio de frontera geográfica enunciativa vivenciado aquí en la Triple Frontera por las instituciones de enseñanza y se dirige al presupuesto de que al aprender una lengua el estudiante brasileño se completa en cuanto a sujeto activo en sociedad, pues "se centra en cómo los conocimientos producidos pueden traer beneficios sociales para las

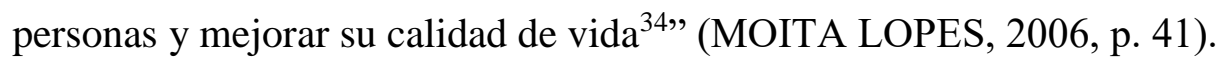

Su fundamentación teórica, además de considerar a diversos lingüistas, está basada en las investigaciones realizadas por Ribeiro (2015) en su tesis de doctorado, en la cual fue analizada la situación de la Lengua Española como Lengua de Frontera de la ciudad de Guaira, Paraná, situación similar a la vivenciada en la ciudad cede de este proyecto de extensión. De los datos obtenidos, se destaca que los Entrevistados de su estudio demostraron interés por la oferta de Lengua Española en las escuelas y reflexionaron sobre la particularidades del municipio y de la presencia de alumnos hablantes de esta lengua, llegando a la conclusión de que su enseñanza/aprendizaje mejoraría la comunicación en el día a día ya sea de forma personal o profesional. Por ello, el proyecto "Ensino de Línguas de

\footnotetext{
32 , Fragmento original: "antes de mais nada, que o verdadeiro propósito do ensino de línguas estrangeiras é formar indivíduos capazes de interagir com pessoas de outras culturas e modos de pensar e agir. Significa transforma-se em cidadão do mundo" (RAJAGOPALAN, 2003, p. 70 - grifos nuestros).

${ }^{33}$ El concepto de enseñanza primaria fue utilizado en esta acción de extensión para representar al Ensino Fundamental I ( $1^{\circ}$ ao $5^{\circ}$ anos $)$ brasileño.

${ }^{34}$ Fragmento original: "foco está em como os conhecimentos produzidos podem trazer ganhos sociais para as pessoas e melhorar sua qualidade de vida" (MOITA LOPES, 2006, p. 41).
} 
Fronteira através de práticas interdisciplinares" visiona que las recompensas para la sociedad iguaçuense también serán considerables.

Así, la metodología utilizada en la ejecución del proyecto y las actividades propuestas constan de una recopilación bibliográfica sobre la enseñanza de lenguas con enfoque en la Lingüística Aplicada, al establecer una correlación entre los presupuestos de las Políticas Lingüísticas, los Derechos Lingüísticos y la Sociolingüística hacia la enseñanza de Lenguas. Para ello, a partir de una investigación in loco y de la observación participante ${ }^{35}$, se desarrollaron diferentes prácticas de enseñanza y de investigación que implican lecturas y discusiones de artículos y otros textos en Lengua Adicional y alfabetización en los primeros años.

Para cumplir con el carácter interdisciplinario, las actividades tendrán temáticas diversas y se desarrollarán a través de prácticas diferenciadas, atendiendo a las necesidades de la comunidad involucrada.

\section{Chachalacas, español para niños}

Lo que justifica que niños aprendan una LE [Lengua Extranjera], es para tener acceso a diferentes culturas existentes y que las circundan, y a través de esas diferentes culturas saber valorar y convivir con personas de diferentes razas, etnias, géneros, edades, orientaciones religiosas y así enseñar a través de la LE y poder entender la noción de ciudadanía y ética y que ultrapasan los valores culturales de cada ciudadano ${ }^{36}$.

(FERREIRA, 2013, p. 13).

Ferreira (2013), al prologar la segunda edición del libro Ensino de língua estrangeira para crianças: o ensino e a formação em foco, justifica muy bien la importancia y la necesidad de ensenar otras lenguas a los niños. Aunque la autora se utiliza del término Lengua Extranjera, el presupuesto de enseñanza se aplica a los conceptos de Lengua Adicional y de

\footnotetext{
35 Asociación con el Proyecto de Investigación "Ensino de línguas de fronteira sob a perspectiva de fronteira geográfica enunciativa" (UNILA).

${ }^{36}$ Fragmento original: “que justifica que crianças aprendam uma LE [Língua Estrangeira], é para ter acesso a diferentes culturas existentes e que as circundam, e através dessas diferentes culturas saber valorizar e conviver com pessoas de diferentes raças, etnias, gêneros, idades, orientações religiosas e assim ensinar através da LE e poder entender a noção de cidadania e ética e que perpassam os valores culturais de cada cidadão" (FERREIRA, 2013).
} 
Lengua de Frontera, a si considerar el espacio de frontera geográfica enunciativa vivenciado aquí en la Triple Frontera (Brasil, Paraguay y Argentina).

Delante de esto y partiendo de lo que establecen Ferreira (2013) y Ribeiro (2015, 2017) es que se pensó y se propuso la ejecución de un curso de español para los niños. Así, el curso Chachalacas, español para niños es una iniciativa de la Acción de Extensión "Ensino de Línguas de Fronteira através de práticas interdisciplinares"37, a ser desarrollado en la UNILA. Destinado a niños de la enseñanza primaria, tendrá su primera ejecución en el segundo semestre de 2017. El objetivo del curso es llevar la lengua española al espacio de la escuela, en principio a los alumnos brasileños, posteriormente a los profesores y equipos pedagógicos, y hacer un trabajo en conjunto con el Proyecto "Ensino de Português como Língua Adicional no Ensino Fundamental I" que pretende enseñar la Lengua Portuguesa a estudiantes hispanohablantes bajo la perspectiva de Lengua Adicional y no Portugués como Lengua Materna ${ }^{38}$, como ocurre en los salones de clases de gran parte de las escuelas.

El concepto que se considera de Lengua Adicional en este estudio es el de lengua en cuanto incremento, o sea, conforme a lo dispuesto por Rodrigues, el "termino Lengua Extranjera está intrínsecamente ligado a nociones de HN [hablante nativo] y HNN [hablante no-nativo], [...] Lengua Adicional ${ }^{39 "}$ consiste en el "incremento de una lengua a otras que el alumno tenga en su repertorio y se reconozca ${ }^{40 "}$ (RODRIGUES, 2013, p. 17). Si bien muchos hablantes extranjeros terminan perdiendo el vínculo con su lengua materna, sea por el desuso y falta de contacto con otros hablantes, la Lengua Portuguesa pasa a ser su Segunda Lengua.

El concepto de incremento en la enseñanza de lenguas considera que al aprender otra lengua el sujeto desarrollará una "mejor conciencia sobre su propia lengua, eso permitirá que ese niño aprenda también sobre criticidad" ${ }^{41 "}$ (FERREIRA, 2013, p. 13), pues "las lenguas son la expresión misma de las identidades de quienes se apropian de ellas. El que transita

\footnotetext{
${ }^{37}$ Coordinado por Simone Beatriz Cordeiro Ribeiro y ejecutado por las alumnas Cinthia Itatí Gabriela Minuzzo (LAMC) y Diana Jazmin Britez Cohene (DRUSA).

${ }^{38}$ Ribeiro (2015) aclara que "embora seja um estrangeiro [hispanohablante] que está em contexto de imersão, lhe é ensinada a Língua Portuguesa a partir de abordagens de ensino de Língua Materna porque o mesmo não está frequentando um curso de Português Língua Adicional” (RIBEIRO, 2015).
}

\footnotetext{
${ }^{39}$ Fragmento original: "termo Língua Estrangeira está intrinsecamente ligado à noções de FN [falante nativo] e FNN [falante não-nativo], [...] Língua Adicional”

${ }^{40}$ Fragmento original: "acréscimo de uma língua a outras que o aluno tenha em seu repertório e se reconhece" (RODRIGUES, 2013, p. 17).

${ }^{41}$ Fragmento original: "melhor consciência sobre a sua própria língua, isso permitirá que essa criança aprenda também sobre criticidade" (FERREIRA, 2013, p. 13)
} 
entre diversos idiomas está redefiniendo su propia identidad ${ }^{42 ”}$ (RAJAGOPALAN, 2003, p. 69), redefiniéndose en cuanto a sujeto activo en sociedad.

El objetivo es el de complementar los saberes y no reducirlos a concepciones y prácticas del monolingüismo. No se puede permitir que el bilingüismo sea borrado por políticas lingüísticas en favor del monolingüismo, aún más en espacios transfronterizos en que el contacto con otras lenguas y culturas es cotidiano, una vez que como bien postula Rajagopalan (2003), el ciudadano emergente es multilingüe.

Así, por medio de lo establecido en Lingüística Aplicada, los Derechos Lingüísticos, las Políticas y Planificaciones Lingüísticas, la Sociolingüística y la Enseñanza de Lenguas de Frontera, se propone este curso de español a través de prácticas interdisciplinarias, con vistas a la incorporación de nuevos saberes. Desde una perspectiva en la cual el sujeto pueda utilizar la Lengua de Frontera en su día a día y en los distintos espacios transfronterizos de la Triple Frontera.

\section{Resultados esperados}

La finalidad del proyecto es contribuir a una integración entre la comunidad y la Universidad, por medio de la enseñanza/aprendizaje de Lenguas de Frontera, proporcionando no solo el aprendizaje de una nueva lengua y su repertorio lingüístico, si no que propiciando la integración entre discentes nativos y extranjeros por medio del aprendizaje de la cultura del otro, disminuyendo los espacios transfronterizos que separan paraguayos, argentinos y brasileños, comprendiendo que una lengua, así como su cultura, son tan importantes cuanto la otra.

También se espera que a través del desarrollo del proyecto la discriminación, los prejuicios y los estereotipos se reduzcan o incluso extingan y que los brasileños comprendan la necesidad de aprender la lengua de sus vecinos, ya sea para la comunicación e integración o para enriquecer su repertorio lingüístico. Con respeto a los maestros y equipos pedagógicos de las escuelas, se pretende que el conocimiento de la Lengua Española contribuya en la relación comunicativa e interactiva con los alumnos extranjeros, posibilitando un mejor entendimiento enunciativo y una progresión más eficaz en el aprendizaje de la Lengua Portuguesa por los mismos.

\footnotetext{
${ }^{42}$ Fragmento original: “as línguas são a própria expressão das identidades de quem delas se apropria. Logo quem transita entre diversos idiomas está redefinindo sua própria identidade” (RAJAGOPALAN, 2003, p. 69)
} 


\section{Consideraciones preliminares}

Se puede decir, hasta ahora, que el desarrollo del Proyecto va muy bien. La aceptación por la escuela fue maravillosa y el trabajo ya ejecutado tuvo una recepción y un intercambio de conocimientos muy provechoso.

El desarrollo del Proyecto de Extensión "Ensino de Línguas de Fronteira através de práticas interdisciplinares" en conjunto con el Proyecto también de Extensión "Ensino de Português como Língua Adicional no Ensino Fundamental I", involucrados por el Proyecto de Investigación "Ensino de línguas de fronteira sob a perspectiva de fronteira geográfica enunciativa" parte de una perspectiva de investigación in loco, bibliográfica y observación participante, donde los ejecutores de los proyectos caminan tanto en la investigación cuanto en la práctica, estableciendo una relación de (re)construcción mientras sujetos en sociedad y ciudadanos multilingües en el mundo.

Así, se transita desde la perspectiva de la investigación hasta la práctica pedagógica de ejecución. Una interacción entre enseñanza, investigación y extensión, como postula la Universidad, con el objetivo de compartir saberes y enriquecer sus propias trayectorias científicas y académicas. Como dijo Rajagopalan (2003), no se trata de contabilizar ganancias o pérdidas, pues "es en el lenguaje y a través de él que nuestras personalidades son constantemente sometidas a un proceso de reformulación ${ }^{43}$ " (RAJAGOPALAN, 2003, p. 70). La certeza que tenemos es la de que "nosotros simplemente nos transformamos en otras personas $^{44 "}$ (RAJAGOPALAN, 2003, p. 70).

\section{Referencias}

ALMEIDA FILHO, José C. P. Ensino de Línguas: harmonizar com aquisição, história do ensino de línguas, políticas públicas e uma ética profissional. In PALLÚ, Nelza M. (Org.). Anais da $14^{a}$ Jornada de Estudos Linguísticos e Literários: as línguas em diálogo: perspectivas e desafios na atualidade. Maringá: Gráfica Sthampa, 2011, p. 13-22.

CALVET, L. J. Sociolinguística: uma introdução crítica. Traducción de Marcos Marcionilo. São Paulo: Parábola, 2002.

As políticas lingüísticas. Traducción de Isabel de Oliveira Duarte, Jonas Tenfen y Marcos Bagno. São Paulo: Parábola, 2007.

\footnotetext{
43 Fragmento original: "é na linguagem e através dela que as nossas personalidades são constantemente submetidas a um processo de reformulação” (RAJAGOPALAN, 2003, p. 70).

${ }^{44}$ Fragmento original: "Nós simplesmente nos transformamos em outras pessoas" (RAJAGOPALAN, 2003, p. 70 - en el íntegro).
} 
CAMPIGOTO, José A. Hermenêutica da fronteira: a fronteira entre o Brasil e o Paraguai. Florianópolis, 2000. Tesis de Doctorado en Historia. Universidade Federal de Santa Catarina. Centro de Filosofia e Ciências Humanas. Florianópolis, 2000.

FERREIRA, Aparecida de J. Prefácio à 2a edição: Ensino de Língua Estrangeira para crianças e a formação de professores. In TONELLI, Juliana R. A; CHAGURI, Jonathas de P. (Orgs.). $O$ ensino de língua estrangeira para crianças: o ensino e a formação em foco. 2. ed. Curitiba: Appris, 2013, p. 11-14.

FERREIRA, Ivana K. de S; SANTOS, Liliana F. dos. A aprendizagem de língua estrangeira nos anos iniciais do Ensino Fundamental. Revista Letrônica, v. 3, n. 1, jul. 2010, p. 128-141, 2010. Disponible

en <<revistaseletronicas.pucrs.br/ojs/índex.php/letronica/article/view/6930/5468〉> Acceso en jan. 2015

MARCO DAS TRÊS FRONTEIRAS. Disponible en $<<$ http://wikimapia.org/26932/pt/Marco-das-Tr\%C3\%AAs-Fronteiras-Tr\%C3\%ADpliceFronteira > Acceso en jul. 2017

MOITA LOPES, Luiz P. Da. (Org.). Por uma linguística aplicada INdisciplinar. São Paulo: Parábola, 2006.

MÓR, Walkyria M. As políticas de ensino de línguas e o projeto de letramentos. In NICOLAIDES, Christine et al. (Orgs.). Política e políticas linguísticas. Campinas, SP: Pontes, 2013, p. 219-236.

OLIVEIRA, Gilvan M. de. Políticas linguísticas como políticas públicas. 2013. Disponible en $<<$ http://e-ipol.org/wp-

content/uploads/2013/06/Politicas_linguisticas_e_Politicas_publicas.pdf $\gg$ Acceso en set. 2013.

. Política Linguística na e para além da Educação Formal. Estudos linguísticos XXXIV, p. 87-94, 2005. Disponible en $<<$ http://etnolinguistica.wdfiles.com/local-files/journal\%3Aestudos/oliveira_2005 politica.pdf $>>$ Acceso en set. 2013.

PEREIRA, Maria C; COSTA, Rinaldo V. Políticas lingüística: o caso dos cenários bi(multi)língues. In VON BORSTEL, Clarice N. e COSTA-HÜBES, T. da C. (Orgs.). Linguagem, Cultura e Ensino. Cascavel: EDUNIOESTE, 2011, p. 49- 66.

RAJAGOPALAN, Kanavillil. Língua Estrangeira e autoestima. Por uma linguística crítica: linguagem, identidade e a questão ética. São Paulo: Parábola, 2003, p. 65-70.

Política linguística: do que é que se trata, afinal? In NICOLAIDES, Christine et al. (Orgs). Política e políticas lingüísticas. Campinas, SP: Pontes, 2013, p, 19-42.

RIBEIRO, Simone B. C. Língua(s) de fronteira: o ensino da língua espanhola em Guaíra, Paraná. Cascavel, 2015. Tesis de Doctorado. Unioeste, 2015. 
; Políticas línguísticas e ensino de língua(s) de fronteira na escola. In Revista Organon. v. 32, n. 62, junho de 2017, p. 1-17, 2017 Disponible en <<http://seer.ufrgs.br/index.php/organon/article/view/72274>> Acceso en jul. 2017

RODRIGUES, Bruno C. Ensino de português como língua adicional para hispanofalantes: uma proposta de material didático para o ensino de leitura e escrita em níveis iniciais. Porto Alegre, 2013. Monografía de conclusión de curso. Universidade Federal do Rio Grande do Sul. Instituto de Letras. 2013.

SALINAS, Arturo. Ensino de espanhol para brasileiros: destacar o uso ou a forma? In SEDYCIAS, João. (Org.). O ensino do espanhol no Brasil: passado, presente, futuro. São Paulo: Parábola Editorial, 2005, p. 54-60.

SEDYCIAS, João. Por que os brasileiros devem aprender espanhol? In SEDYCIAS, João (Org.). O ensino do espanhol no Brasil: passado, presente, futuro. São Paulo: Parábola Editorial, 2005, p. 35-44.

SILVA, K. A.; SANTOS, L. I. S.; JUSTINA, O. D. Entrevista com Kanavillil Rajagopalan: ponderações sobre linguística aplicada, política linguística e ensino-aprendizagem. Revista de Letras Norte@mentos - Revista de Estudos Linguísticos e Literários. Edição 08 - Estudos Linguísticos 2011/02. Disponible en: http://projetos.unematnet.br/revistas_eletronicas/index.php/norteamentos Acceso en marzo de 2014.

STURZA, Eliana R. Línguas de Fronteira e Políticas de línguas: uma história das idéias linguísticas. Campinas, 2006. Tesis de Doctorado. Campinas. UNICAMP, 2006.

VON BORSTEL, Clarice N. Políticas linguísticas e educacionais em situações de línguas em/de contato. LLJournal, v. 8, n. 1, p.1-10. 2013. Disponible en http://ojs.gc.cuny.edu/index.php/lljournal/article/view/1365/1452 Acceso en jun. 2016. 